\title{
Protective Effects of Histidine Dipeptides on the Modification of Neurofilament-L by the Cytochrome $c /$ Hydrogen Peroxide System
}

\author{
Nam Hoon Kim and Jung Hoon Kang* \\ Department of Genetic Engineering, Cheongju University, Cheongju 360-764, Korea
}

Received 7 September 2006, Accepted 19 October 2006

\begin{abstract}
Neurofilament-L (NF-L) is a major element of the neuronal cytoskeleton and is essential for neuronal survival. Moreover, abnormalities in NF-L result in neurodegenerative disorders. Carnosine and the related endogeneous histidine dipeptides prevent protein modifications such as oxidation and glycation. In the present study, we investigated whether histidine dipeptides, carnosine, homocarnosine, or anserine protect NF-L against oxidative modification during reaction between cytochrome $c$ and $\mathrm{H}_{2} \mathrm{O}_{2}$. Carnosine, homocarnosine and anserine all prevented cytochrome $c / \mathrm{H}_{2} \mathrm{O}_{2}$-mediated NF-L aggregation. In addition, these compounds also effectively inhibited the formation of dityrosine, and this inhibition was found to be associated with the reduced formations of oxidatively modified proteins. Our results suggest that carnosine and histidine dipeptides have antioxidant effects on brain proteins under pathophysiological conditions leading to degenerative damage, such as, those caused by neurodegenerative disorders.
\end{abstract}

Keywords: Carnosine, Cytochrome $c$, Modification, Neurofilament-L

\section{Introduction}

Previous studies have suggested that abnormal protein aggregation is associated with the pathogenesis of neurodegenerative disorders (Lansbury, 1999). In Parkinson's disease (PD), a neurodegenerative disorder associated with dopaminergic nerve cell loss and the presence of neuronal inclusion bodies and dystrophic neurites in the substantia nigra and various other brain regions (Forno, 1996). Lewy bodies (LBs), which are cytoplasmic inclusions, are characteristically present and show greatest frequency in the neurons of the substantia nigra

\footnotetext{
*To whom correspondence should be addressed.

Tel: 82-431-229-8562; Fax: 82-431-229-8432

E-mail : jhkang@cju.ac.kr
}

and locus ceruleus of PD patients (Forno, 1986). Ultrastructurally, LBs are visualized as being composed primarily of a filamentous mesh that surrounds a compact core. Moreover, all three neurofilament (NF) subunit proteins, i.e., heavy (NF$\mathrm{H})$, medium (NF-M), and light (NF-L), have been identified immunohistochemically as major components of LB filaments (Pollanen et al., 1993; Trojanoski et al., 1993).

Cytochrome $c$ is an electron transport protein which catalyses peroxidase-like reactions in vitro (Radi et al., 1991a). Moreover, defective mitochondrial function has been found in brain, muscle and peripheral tissues, such as, platelets and fibroblasts in PD (Parker and Swerdlow, 1998). And, oxidative stress has been identified to be a factor involved in the release of cytochrome $c$ from mitochondria to cytosol (Reed, 1997; Stridh et al., 1998; Ma et al., 1999), which is component of the trigger initiating the cascade of events that lead to apoptosis. Not surprisingly, increased levels of apoptosis have been reported to be associated with neurodegenerative diseases (Gorman et al., 1996; Schapira, 1999). Therefore, we hypothesized that oxidative damage to cytochrome $c$ may increase during neurodegenerative diseases like PD.

Carnosine ( $\beta$-alanyl-L-histidine), a natural occurring dipeptide, was first discovered by Gulewitsch and Amiradzibi (1900) in meat extract in 1900. Carnosine accumulates in the excitable tissues (brain and skeletal muscle) of vertebrates in large amounts and may reach more $10 \mathrm{mM}$ per $\mathrm{Kg}$ (wet weight) (Abe, 1995). Moreover, several biochemical studies have concluded that carnosine possesses antioxidant and free radical-scavenging functions, which may partly explain its apparent homeostatic function (Auroma et al., 1989; Hartman et al., 1990). In addition, some related compounds, i.e., anserine ( $\beta$-alanyl-3-methyl-L-histidine) and homocarnosine ( $\gamma$-amino butyryl-L-histidine), have been reported to be present at millimolar concentrations in several mammalian tissues, including brain and skeletal muscle, although they show interesting differences in tissue distribution (Crush, 1970; O'Dowd et al., 1988). These derivatives have also shown antioxidant, proton buffering, or heavy metal chelating abilities in simple chemical models (Bolyrev et al., 1995; Boldyrev 
and Abe, 1999), but their biological activities have not been clarified. Although many studies have been conducted on the protective effects of carnosine and carnosine-related compounds on oxidative proteins damage, the inhibitory actions of these compounds on cytochrome $c$-mediated NF-L modifications are unknown. In the present study, we examined the protective effects of carnosine, homocarnosine, or anserine on cytochrome $c / \mathrm{H}_{2} \mathrm{O}_{2}$-mediated NF-L aggregation.

\section{Materials and Methods}

Materials. Cytochrome $c$, carnosine, homocarnosine, anserine, ethylene glycol-bis(2-amino ethyl ether)- $N, N, N^{\prime}, N^{\prime}$-tetraacetic acid (EGTA), dithiothreitol (DTT), sodium dodecyl sulfate (SDS), and monoclonal anti-neurofilament 68 antibody (mouse) were purchased from Sigma Chemical Co. Chelex 100 resin (sodium form) was obtained from Bio-Rad.

Preparation of neurofilament-L. The protein expression of NF-L and its purification were performed as previously described (Kim and Kang, 2003). Full-length cDNA clones of mouse NF-L in pET$3 \mathrm{~d}$ vector were transfected into $E$. coli (BL21), and transfected bacteria at an OD $600 \mathrm{~nm}$ of 0.8 were grown in Luria broth supplemented with $1 \mathrm{mM}$ isopropyl $\beta$-D-thiogalactopyranoside. Incubation was performed at $37^{\circ} \mathrm{C}$ for $3 \mathrm{~h}$. Bacteria were then harvested by centrifugation $\left(4,000 \times g\right.$ for $10 \mathrm{~min}$ at $\left.4^{\circ} \mathrm{C}\right)$, resuspended in standard buffer (50 mM MES, $170 \mathrm{mM} \mathrm{NaCl}, 1 \mathrm{mM}$ DDT, $\mathrm{pH}$ 6.25), disrupted using a French press at 20,000 p.s.i., and centrifuged at $8,000 \times g$ for $15 \mathrm{~min}$ at $4^{\circ} \mathrm{C}$. Supernatant was incubated for $3 \mathrm{~h}$ at $37^{\circ} \mathrm{C}$ and then centrifuged at $100,000 \times g$ for $20 \mathrm{~min}$ at $25^{\circ} \mathrm{C}$. The pellets containing the aggregated NF-L proteins were washed twice with standard buffer before being dissolved in urea buffer $(2 \mathrm{mM}$ Na-phosphate, pH 7.5, 6 M urea, $1 \mathrm{mM}$ EGTA and $1 \mathrm{mM}$ DTT). Samples were loaded onto a DEAE-Sepharose column and eluted with a linear $25-500 \mathrm{mM}$ phosphate gradient in urea buffer; NF-L eluted between 300 and $360 \mathrm{mM}$ phosphate. These fractions were pooled and either used directly or stored at $-80^{\circ} \mathrm{C}$ for later experiments. Protein concentration was determined using the BCA method (Smith et al., 1985)

Analysis of NF-L modification. NF-L was oxidatively modified by incubating NF-L $(0.25 \mathrm{mg} / \mathrm{ml})$ with $10 \mathrm{mM}$ cytochrome $c$ and $500 \mathrm{mM} \mathrm{H} \mathrm{H}_{2} \mathrm{O}_{2}$ in $10 \mathrm{mM}$ phosphate buffer (pH 7.4) at $37^{\circ} \mathrm{C}$. Reactions were stopped by freezing at $-80^{\circ} \mathrm{C}$, and then treated with a $4 \times$ concentrated sample buffer $(0.25 \mathrm{mM}$ Tris-HCl, $8 \%$ SDS, $40 \%$ glycerol, $20 \%$ b-mercaptoethanol, $0.01 \%$ bromophenol blue) and heated in boiling water for $10 \mathrm{~min}$. An aliquot of each sample was then subjected to SDS-polyacrylamide gel electrophoresis (PAGE), as described by Laemmli (1970), using 12\% acrylamide slab gel. For immunoblotting, proteins on polyacrylamide gels were electrophoretically transferred to nitrocellulose membranes which were then blocked in 5\% nonfat milk in Tris-buffered saline (TBS: $20 \mathrm{mM}$ Tris, $0.2 \mathrm{M} \mathrm{NaCl}, \mathrm{pH} 7.5$ ) containing $0.05 \%$ Tween-20 (TTBS) (Eum et al., 2005). Membranes were incubated for $1 \mathrm{~h}$ at room temperature with anti-NF antibody $(1: 400)$ in TTBS, washed with TBS, and re-incubated with peroxidase labeled secondary

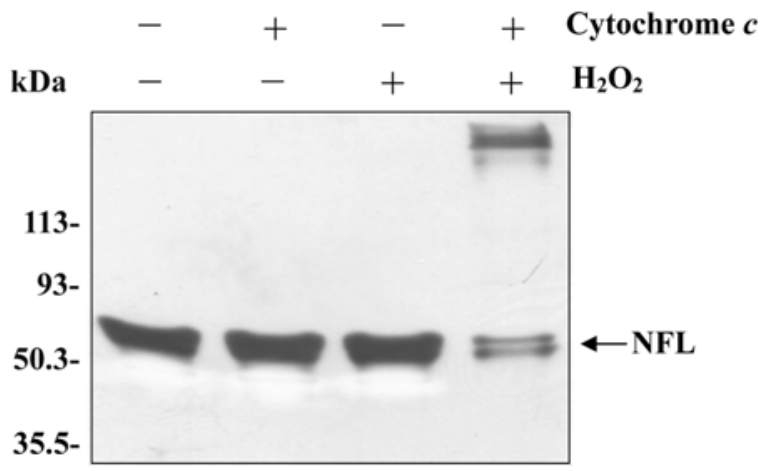

Fig. 1. Aggregation of NF-L by the cytochrome $c / \mathrm{H}_{2} \mathrm{O}_{2}$ system was analyzed by immunoblotting. NF-L $(0.25 \mathrm{mg} / \mathrm{ml})$ was incubated at $37^{\circ} \mathrm{C}$ for $2 \mathrm{~h}$ : Lane 1 , NF-L control; lane $2, \mathrm{NF}-\mathrm{L}+10 \mu \mathrm{M}$ cytochrome $c$; lane $3, \mathrm{NF}-\mathrm{L}+0.5 \mathrm{mM} \mathrm{H}_{2} \mathrm{O}_{2}$; lane $4, \mathrm{NF}-\mathrm{L}+10$ $\mu \mathrm{M}$ cytochrome $c+0.5 \mathrm{mM} \mathrm{H}_{2} \mathrm{O}_{2}$. Reactions were stopped by freezing at $-80^{\circ} \mathrm{C}$.

antibody. The protein bands were visualized using an enhanced chemiluminescence kit (ECL; PerkinElmer).

Detection of $\mathbf{O}, \mathrm{O}^{\prime}$-dityrosine. $\mathrm{O}, \mathrm{O}^{\prime}$-dityrosine was detected using NF-L $(0.25 \mathrm{mg} / \mathrm{ml}), 10 \mu \mathrm{M}$ cytochrome $c$ and $500 \mu \mathrm{M} \mathrm{H}_{2} \mathrm{O}_{2}$ in a total volume of $300 \mu \mathrm{l}$. Briefly, samples were diluted with $2.7 \mathrm{ml}$ of Chelex 100-treated water and transferred to a cuvette $(3 \mathrm{ml})$. Sample fluorescence was monitored at $410 \mathrm{~nm}$ (emission) and at $325 \mathrm{~nm}$ (excitation) using a fluorescence spectrometer SMF 25 (Bio-Tek Instruments).

Replicates. Unless otherwise indicated, each result described in this paper is representative of at least three separate experiments.

\section{Results and Discussion}

Figure 1 shows an original intact NF-L band after incubation with $10 \mu \mathrm{M}$ cytochrome $c$ or $500 \mu \mathrm{M} \mathrm{H}_{2} \mathrm{O}_{2}$. However, when NF-L was incubated in a mixture of cytochrome $c$ and $\mathrm{H}_{2} \mathrm{O}_{2}$ protein aggregation occurred. Thus, indicating that both cytochrome $c$ and $\mathrm{H}_{2} \mathrm{O}_{2}$ are required for the aggregation of NF-L. It was postulated that hydrogen peroxide, like peroxidases, oxidizes cytochrome $c$ to an oxoferryl derivative. The oxoferryl cytochrome $c$ then catalyzes the oxidation of biomolecules (Radi et al., 1991a; Radi et al., 1993b; Kim and Kang, 2006). Therefore, we reasoned that an oxoferryl derivative may be involved in cytochrome $c$-mediated NF-L aggregation. Moreover, it has been suggested that mitochondrial dysfunction may be involved in the pathogenesis of neurodegenerative disorders. (Schapira, 1994) The present study suggests that oxidative damage of NF-L by the cytochrome $c / \mathrm{H}_{2} \mathrm{O}_{2}$ system might occur in diseases like Parkinson's disease, associated with mitochondrial dysfunction.

Carnosine and its related compounds have been proposed to act as antioxidants, free radical scavengers, physiological buffering agents, neurotransmitters, radioprotectants, metal 

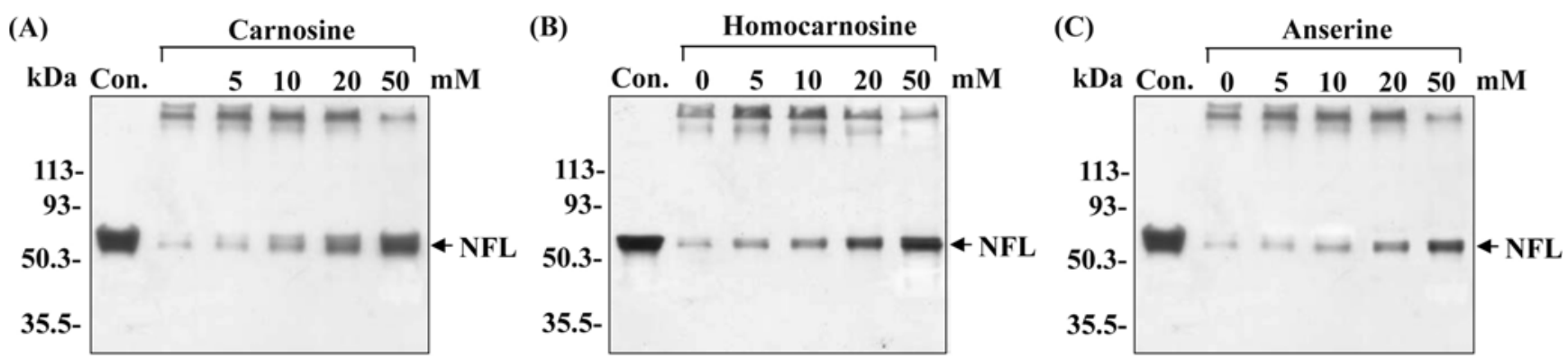

Fig. 2. Effects of carnosine, homocarnosine, or anserine on the aggregation of NF-L by the cytochrome $c / \mathrm{H}_{2} \mathrm{O}_{2}$ system. NF-L was incubated with $10 \mu \mathrm{M}$ cytochrome $c$ and $0.5 \mathrm{mM} \mathrm{H}_{2} \mathrm{O}_{2}$ in various concentrations of carnosine (A), homocarnosine (B), or anserine (C) at $37^{\circ} \mathrm{C}$ for $2 \mathrm{~h}$. Lane 1 , cytochrome $c$ control; lane 2, incubated with $\mathrm{H}_{2} \mathrm{O}_{2}$; lane 3, $5 \mathrm{mM}$ effectors; lane $4,10 \mathrm{mM}$ effectors; lane 5 , $20 \mathrm{mM}$ effectors; lane $6,50 \mathrm{mM}$ effectors. Protein oligomerization was analyzed by immunoblotting.
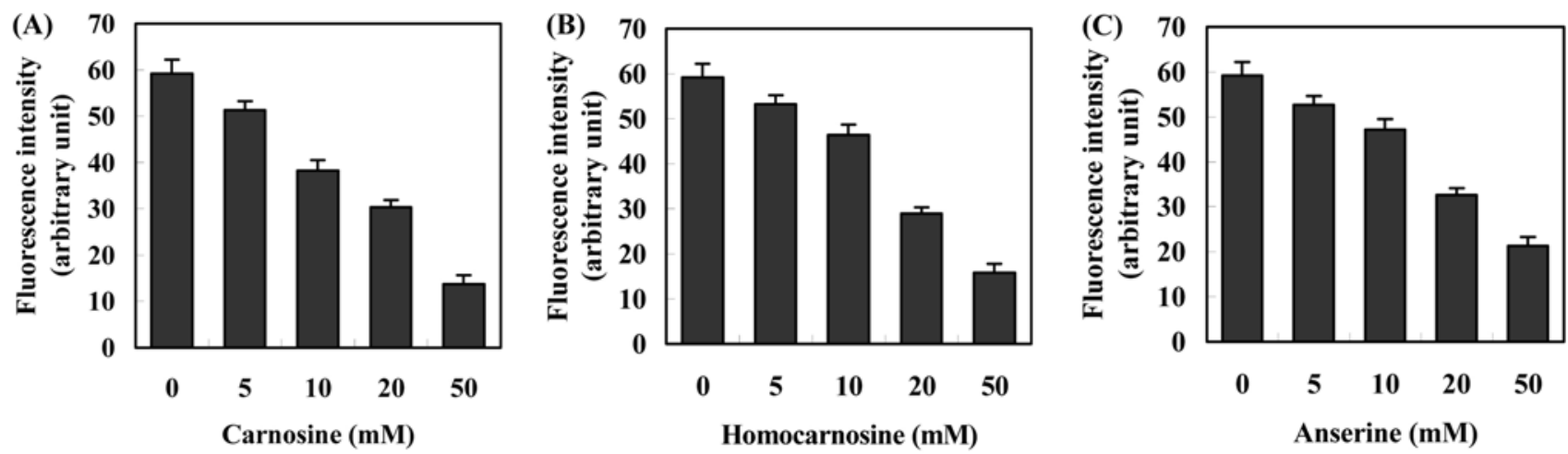

Fig. 3. Effects of carnosine, homocarnosine, or anserine on the formation of dityrosine in cytochrome $c / \mathrm{H}_{2} \mathrm{O}_{2}$-induced NF-L aggregates. $10 \mu \mathrm{M}$ cytochrome $c$ was incubated with $0.5 \mathrm{mM} \mathrm{H}_{2} \mathrm{O}_{2}$ in the presence of various concentrations of carnosine, homocarnosine, or anserine at $37^{\circ} \mathrm{C}$ for $2 \mathrm{~h}$. Reaction mixtures were analyzed by fluorescent spectrometry. Data represent means $\pm \mathrm{SD}(\mathrm{n}=3-5)$.

chelators, and wound healing agents (Brown, 1981; Boldyrev et al., 1988; Auroma et al., 1989). In the present study, it was found that carnosine, homocarnosine, and anserine all significantly inhibited the NF-L aggregation induced by the cytochrome $c / \mathrm{H}_{2} \mathrm{O}_{2}$ system (Fig. 2). In addition, it has been reported that imidazole-containing peptides, which are also carnosine and related compounds, may react with di- or monoaldehydes (powerful cross-linking agents) released during the oxidative breakdown of unsaturated lipids (Aldini et al., 2002). Our data suggest that the imidazolium group of carnosine might inhibit the formation of the oxoferryl derivative. Along with carnosine, homocarnosine and $\mathrm{N}$-acetyl-histidine are accumulated in normal brain, whereas anserine and ophidine ( $N^{1}-$ and $N^{3}$-methylated carnosine derivatives, respectively) specifically accumulate in the skeletal muscles of birds, some fishes, and marine mammals (Abe, 1995). Therefore, in brain, carnosine and homocarnosine may play a critical role in the protection of proteins against oxidative damage. We also investigated whether carnosine and its related compounds could inhibit dityrosine formation. When NF-L was incubated with cytochrome $c$ and $\mathrm{H}_{2} \mathrm{O}_{2}$ in the presence of carnosine, homocarnosine or anserine, they were found to effectively inhibit dityrosine formation (Fig. 3).
Dityrosine is a biomarker of protein oxidation (Giulivi and Davies, 1993; Heinecke and Daehnke 3rd, 1993; Huggins et al., 1993) and is found in the amino acid hydrosylates of brain tissues affected by neurodegenerative disorders (Pennathur et al., 1999). Moreover, recent studies have suggested that the oxidative cross-linking of proteins by tyrosine residues occur via a peroxidase-like mechanism. The proposed mechanism for the reaction between $\mathrm{H}_{2} \mathrm{O}_{2}$ and ferricytochrome $c$ owes a great deal to our knowledge of the reaction between $\mathrm{H}_{2} \mathrm{O}_{2}$ and the heme-containing peroxidase enzymes (Kato et al., 2001; Atwood et al., 2004). If two adjacent tyrosine radicalcontaining molecules interact, a dityrosine-linked dimer is formed. It has been reported that the exposure of $\alpha$-synuclein (a neuronal presynaptic protein) to nitrating agents led to tyrosine oxidation to form o,o'-dityrosine, and crosslinking of $\alpha$-synuclein to form stable high molecular mass $\alpha$-synuclein aggregates (Olteanu and Pielak, 2004). NF-L is susceptible to oxidation because it is among the most abundant proteins in neuronal cells and because it contains a large molar fraction of tyrosine. Our data suggest that carnosine, homocarnosine, and anserine protect against NF-L aggregation caused by oxidative damage by cytochrome $c / \mathrm{H}_{2} \mathrm{O}_{2}$ by inhibiting dityrosine formation. 
The data presented here are consistent with the inhibition of the cytochrome $c / \mathrm{H}_{2} \mathrm{O}_{2}$-mediated modification of NF-L by carnosine, homocarnosine, or anserine. Our findings indicate that these compounds should be further explored as potential therapeutic agents that counteract the oxidative stress associated with neurodegenerative disorders like Parkinson's disease.

\section{References}

Abe, H. (1995) Histidine-related dipeptides: distribution, metabolism and physiological function; in Biochemistry and Molecular Biology of Fishes, Hochachka, P. W. and Mommensen, T. P. (eds), pp. 310-333, Elsevier Science, Amsterdam, Netherlands.

Aldini, G., Carini, M., Beretta, G., Bradamante, S. and Facino, R. M. (2002) Carnosine is a quencher of 4-hydroxy-nonenal: through what mechanism of reaction? Biochem. Biophys. Res. Commun. 298, 699-706.

Atwood, C. S., Perry, G., Zeng, H., Kato, Y., Jones, W. D., Ling, K. Q., Huang, X., Moir R. D., Wang, D., Sayre, L. M., Smith, M. A., Chen, S. G. and Bush, A. I. (2004) Copper mediates dityrosine cross-linking of Alzheimer's amyloid-beta. Biochemistry 43, 560-568.

Auroma, O. I., Laughton, M. J. and Halliwell, B. (1989) Carnosine, homocarnosine and anserine: could they act as antioxidants in vivo? Biochem. J. 264, 863-869.

Boldyrev, A. and Abe, H. (1999) Metabolic transformation of neuropeptide carnosine modifies its biological activity. Cell Mol. Neurobiol. 19, 163-175.

Boldyrev, A., Abe, H., Stvolinsky, S. L. and Tyulina, O. V. (1995) Effects of carnosine and related compounds on generation of free radical species: a comparative study. Comp. Biochem. Physiol. B 112, 481-485.

Boldyrev, A. A., Dupin, A. M., Pindel, E. V. and Severin, S. E. (1988) Antioxidative properties of histidine-containing dipeptides from skeletal muscles of vertebrates. Comp. Biochem. Physiol. 89, 245-250.

Brown, C. E. (1981) Interactions among carnosine, anserine, ophidine and copper in biochemical adaption. J. Theor. Biol. 88, 245-256.

Crush, K. G. (1970) Carnosine and related substances in animal tissues. Comp. Biochem. Physiol. 34, 3-10.

Eum, W. S., Choi, H. S., Kim, D. W., Jang, S. H., Choi, S. H., Kim, S. Y., Park, J., Kang, J. H., Cho, S.-W., Kwon, O.-S., Hwang, I. K., Yoo, K.-Y., Kang, T.-C., Won, M. H. and Choi, S. Y. (2005) Production and characterization of monoclonal antibodies against human ceruloplasmin. J. Biochem. Mol. Biol. 38, 71-76.

Forno, L. S. (1986) The lewy body in Parkinson's disease. $A d v$. Neurol. 45, 35-42.

Forno, L. S. (1996) Neuropathology of Parkinson's disease. $J$. Neuropathol. Exp. Neurol. 55, 259-272.

Giulivi, C. and Davies, K. J. (1993) Dityrosine and tyrosine oxidation products are endogenous markers for the selective proteolysis of oxidatively modified red blood cell hemoglobin by (the $19 \mathrm{~S}$ ) proteosome. J. Biol. Chem. 268, 8752-8759.

Gorman, A. M., McGowan, A., O’Neill, C. and Cotter, T. (1996) Oxidative stress and apoptosis in neurodegeneration. J. Neurol.
Sci. 139, 45-52.

Gulewitsch, W. and Amiradzibi, S. (1900) Ueber das carnosin, eine neue organische base des fleischextractes. Ber. Dtsh. Chem. Ges. 33, 1902-1903.

Hartman, P. E., Hartman, Z. and Ault, K. T. (1990) Scavenging of singlet molecular oxygen by imidazole compounds: high and sustained activities of carboxy terminal histidine dipeptides and exceptional activity of imidazole-4-acetic acid. Photochem. Photobiol. 51, 59-66.

Heinecke, J. W., Li, W., Daehnke 3rd, H. L. and Goldstein, J. A. (1993) Dityrosine, a specific marker of oxidation, is synthesized by the myeloperoxidase-hydogen peroxide system of human neutrophils and macrophages. J. Biol. Chem. 268, 4069-4077.

Huggins, T. G., Wells-Knecht, M. C., Detorie, N. A., Baynes, J. W. and Thorpe, S. R. (1993) Formation of o-tyrosine and dityrosine in proteins during radiolytic and metal-catalyzed oxidation. J. Biol. Chem. 268, 12341-12347.

Kato, Y., Kitamoto, N., Kawai, Y. and Osawa, T. (2001) The hydrogen peroxide/copper ion system, but not other metalcatalyzed oxidation systems, produces protein-bound dityrosine. Free Radic. Biol. Med. 31, 624-632.

Kim, N. H. and Kang, J. H. (2003) Oxidative modification of neurofilament-L by copper-catalyzed reaction. J. Biochem. Mol. Biol. 36, 488-492.

Kim, N. H. and Kang, J. H. (2006) Oxidative damage of DNA induced by the cytochrome $c$ and hydrogen peroxide system. $J$. Biochem. Mol. Biol. 39, 452-456.

Laemmli, U. K. (1970) Cleavage of structural proteins during the assembly of the head of bacteriophage T4. Nature 227, 680685.

Lansbury, P. T. Jr. (1999) Evolution of amyloid: what normal protein folding may tell us about fibrillogenesis and disease. Proc. Natl. Acad. Sci. USA 96, 3342-3344.

Ma, Y., Ogino, T., Kawabata, T., Eguchi, K. and Okada, S. (1999) Cupric nitrilotriacetate-induced apoptosis in HL-60 cells association with lipid peroxidation, release of cytochrome $c$ from mitochondria, and activation of caspase-3. Free Radic. Biol. Med. 27, 227-233.

O'Dowd, J. J., Robins, D. J. and Miller, D. L. (1988) Detection, characterization, and quantification of carnosine and other histidyl derivatives in cardiac and skeletal muscle. Biochim. Biophys. Acta 967, 241-249.

Olteanu, A. and Pielak, G. J. (2004) Peroxidative aggregation of asynuclein requires tyrosines. Protein Sci. 13, 2852-2856.

Parker, W, D, Jr and Swerdlow, R. H. (1998) Mitochondrial dysfunction in idiopathic Parkinson disease. Am. J. Hum. Genet. 62, 758-762.

Pollanen, M. S., Dickson, D. W. and Bergeron, C. (1993) Pathology and biology of the Lewy body. J. Neuropathol. Exp. Neurol. 52, 183-191.

Radi, R., Thomson, L., Rubbo, H. and Prodanov, E. (1991a) Cytochrome $c$-catalyzed oxidation of organic molecules by hydrogen peroxide. Arch. Biochem. Biophys. 288, 112-117.

Radi, R., Sims, S., Cassina, A. and Turrens, J. F. (1993b) Roles of catalase and cytochrome $c$ in hydroperoxide-dependent lipid peroxidation and chemiluminescence in rat heart and kidney mitochondria. Free Radic. Biol. Med. 15, 653-659.

Reed, J. C. (1997) Cytochrome $c$ : can't live with it-can't live without it. Cell 91, 559-562.

Schapira, A. H. (1994) Evidence for mitochondrial dysfunction in 
Parkinson's disease-a critical appraisal. Mov. Disord. 9, 125138.

Schapira, A. H. (1999) Mitochondrial involvement in Parkinson's disease, Huntington's disease, hereditary spastic paraplegia and Friedreich's ataxia. Biochim. Biophys. Acta 1410, 159-170.

Smith, P. K., Krohn, R. I., Hermanson, G. T., Mallia, A. K., Gartner, F.-H., Provenzano, M. D., Fujimoto, E. K., Goeke, N. M., Olson, B. J. and Klenk, D. C. (1985) Measurement of protein using bicinchoninic acid. Anal. Biochem. 150, 76-85.
Stridh, H., Kimland, M., Jones, D. P., Orrenius, S. and Hampton, M. B. (1998) Cytochrome $c$ release and caspase activation in hydrogen peroxide- and tributyltin- induced apoptosis. FEBS Lett. 429, 351-355.

Trojanoski, J. Q., Schmidt, M. L., Shin, R.-W., Bramblett, G. T., Rao, D. and Lee, V. M.-Y. (1993) Altered tau and neurofilament proteins in neurodegenerative diseases: Diagnostic implications for Alzheimer's disease and Lewy body dementias. Brain Pathol. 3, 45-54. 